\title{
Effective spray for topical anesthesia with fiberscope
}

\author{
Masanori Tsukamoto $^{1} \cdot$ Jun Hirokawa $^{1} \cdot$ Takeshi Yokoyama $^{1}$
}

Received: 1 February 2017 / Accepted: 21 February 2017 / Published online: 9 March 2017

(C) Japanese Society of Anesthesiologists 2017

\section{To the Editor:}

Fiberoptic intubation is an established technique for patients for whom intubation is difficult [1]. Topical anesthesia might be useful for these patients to decrease stress when undergoing fiberoptic intubation. However, there have been no suitable methods for administering topical anesthesia [2]. Our main aim in this study was defined as achieving better conditions for fiberoptic intubation using a manikin.

A fiberscope (Pentax FB-15; HOYA, Tokyo, Japan) with an insertion tube $4.9 \mathrm{~mm}$ in diameter was used. The tip of the fiberscope was placed $2 \mathrm{~cm}$ from the vocal cord of the manikin model. We evaluated using three syringes of different sizes and three different liquids containing indigo carmine (Daiichi Sankyo, Tokyo, Japan), and the remaining space of the syringe was filled with air. The contents of the syringes were sprayed through the channel of the fiberscope, followed by an air flush. The sprayed area from each group was compared using Scheffe's test. The area sprayed via fiberscope using a 5-ml syringe filled with $2 \mathrm{ml}$ liquid and $3 \mathrm{ml}$ air was significantly larger than that achieved using syringes of other sizes (Supplementary Fig. 1). This study was limited in that it involved a manikin model. Further studies involving an actual human subject and liquids of varying viscosities may be required. We achieved better conditions when administering the topical with a 5-ml syringe filled with $2 \mathrm{ml}$ liquid and $3 \mathrm{ml}$ air for fiberoptic intubation using the manikin.

\section{References}

1. Rosenstock CV, Thøgersen B, Afshari A, Christensen AL, Eriksen C, Gätke MR. Awake fiberoptic or awake video laryngoscopic tracheal intubation in patients with anticipated difficult airway management: a randomized clinical trial. Anesthesiology. 2012;116(6):1210-6.

2. Tachihara M, Ishida T, Fukuhara N, Inokoshi Y, Fukuhara A, Saito K, Ishii T, Kanazawa K, Katsuura Y, Munakata M. Catheter spray of lidocaine: a randomized study of topical anesthesia for flexible bronchoscopy. J Jpn Soc Respir Endosc (JJSRE). 2014;36:359-63.
Electronic supplementary material The online version of this article (doi:10.1007/s00540-017-2331-5) contains supplementary material, which is available to authorized users.

\footnotetext{
Masanori Tsukamoto

tsukamoto@dent.kyushu-u.ac.jp

Jun Hirokawa

hj8823@dent.kyushu-u.ac.jp

Takeshi Yokoyama

yokoyama@dent.kyushu-u.ac.jp

1 Department of Dental Anesthesiology, Kyushu University Hospital, 3-1-1 Maidashi, Higashi-ku, Fukuoka 812-8582, Japan
} 